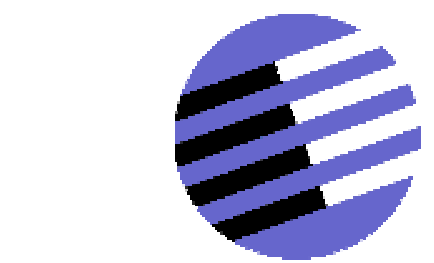

GOVERNANCE AND THE EFFICIENCY

OF ECONOMIC SYSTEMS

GES Y

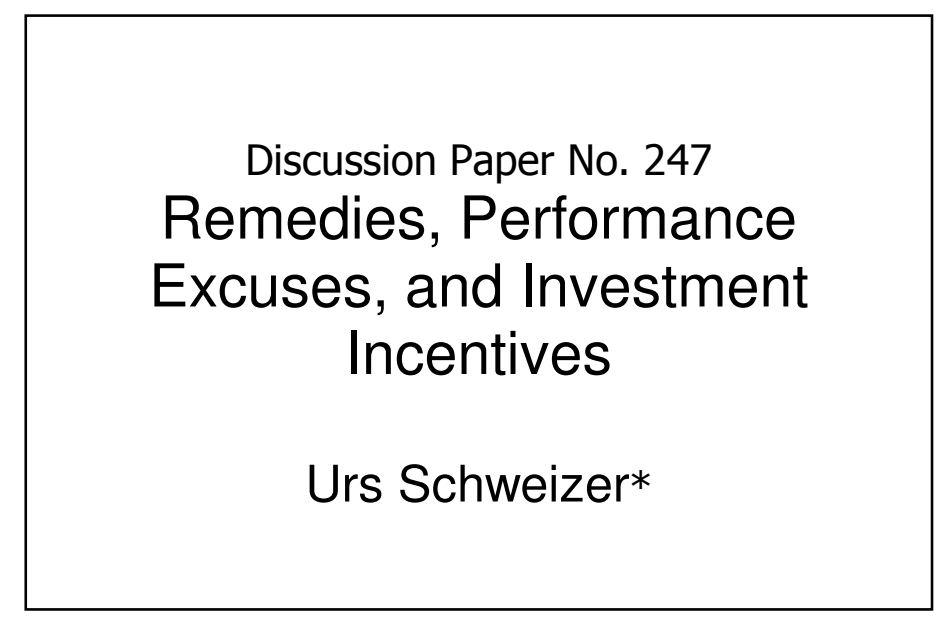

*Urs Schweizer, Department of Economics, University of Bonn, Adenauerallee 24, 53113 Bonn, Germany, schweizer@uni-bonn.de.

September 2008

Financial support from the Deutsche Forschungsgemeinschaft through SFB/TR 15 is gratefully acknowledged. 


\title{
Breach Remedies, Performance Excuses, and Investment Incentives
}

\author{
Urs Schweizer, ${ }^{* \dagger}$ University of Bonn
}

September 23, 2008

\begin{abstract}
Contract law is usually perceived as a strict liability system. When a promisor fails to perform he is held liable even if he is without fault. If, however, an unusual contingency has arisen he may be excused from performing provided that he has taken reasonable precautions. For a setting with uncertain costs of and benefits from performance, it is shown that a fixed price contract is sufficient to generate efficient reliance and precautions incentives under the following legal regime. If the promisor has met the appropriate precaution standard then he is excused if performance fails to be profitable. Alternative regimes, in contrast, where he is excused if performance is inefficient or even is extremely costly distort investment incentives quite generally.
\end{abstract}

JEL classification: K12

Keywords: performance excuse, impracticability doctrine, overreliance, efficient precaution

*address: Urs Schweizer, Department of Economics, University of Bonn, Adenauerallee 24, 53113 Bonn, Germany, schweizer@uni-bonn.de

${ }^{\dagger}$ The author thanks Andrew Daughety, Jennifer Reinganum and seminar participants in Bonn, Hamburg and Munich for useful comments on a previous version of this paper. Support through SFB/TR 15 is also gratefully acknowledged. 


\section{Introduction}

Contract law is usually perceived as a strict liability system. When a promisor fails to perform, he is held liable for the harm caused by his failure to perform even if the promisor is without fault and even if circumstances have made the contract more burdensome than anticipated.

Occasionally, however, if an unusual contingency has arisen as a consequence of which the promisor is facing a dire constraint he may be excused from performing. While there exist several related doctrines, the present paper concentrates on (commercial) impracticability. In practice, performance is excused only when it is extremely costly. Moreover, courts may also examine whether the promisor could have kept costs of performance low by taking reasonable precautions. Nonetheless, defenses such as impracticability to perform import elements of a fault-based system, known from tort law, to contract law as well.

Along these lines, Posner (2008) forcefully argues that the case for strict liability for breach of contract is not particularly strong. He offers an interpretation of the Restatement, $\S 261$, full in line with a negligence regime, under which the promisor is liable if (1) he fails to perform when performance is cost-justified, or (2) he fails to perform and performance is not cost-justified only because the promisor failed to take cost-justified precaution. Posner uses a simple model to show that the negligence regime provides better incentives than the strict liability regime does.

Rational parties anticipate ex post effects from breach remedies and performance excuses when deciding on ex ante investments. The rules in place affect investment decisions and, hence, may be assessed according to the investment incentives they generate. From the economic perspective, it is desirable for rules to generate efficient investment incentives.

Shavell (1980) has examined reliance incentives generated by, among other measures, expectation damages. Expectation damages support the efficient breach of contract but they generate excessive reliance incentives. Along similar lines, Rogerson (1984) has investigated reliance incentives that are generated by specific performance. If performance turns out to be inefficient specific performance serves as threat point for (frictionless) renegotiations. For such a setting, Rogerson has shown that specific performance still 
generates over-reliance though less so than expectation damages.

Combining breach remedies with performance excuses will further affect investment incentives. From an economic perspective, two issues at least are at stake. Posner and Rosenfield (1977) suggest that discharge should be allowed where the promisor is the superior risk bearer. But they also mention the potential use of the impossibility doctrine to optimize reliance incentives. If courts discharge the promisor just in those cases where the promisee has behaved suboptimally such a legal practice would affect reliance incentives indeed. Notice, implementing the scheme under this interpretation of the doctrine would require courts to monitor efficient reliance investments of the promisee.

Sykes (1990) also explores the conditions under which a discharge of contractual obligations is efficient following an event that makes performance impracticable. He examines the scope of the defense both as a risk-sharing device and a leverage against over-reliance. If both parties are risk-neutral, expectation damages as breach remedy if combined with a particular interpretation of the impracticability defense would generate first best reliance incentives. Yet, to implement the rule, courts again would have to determine efficient reliance investments accurately. Sykes concludes from his findings that the information necessary to identify the conditions in practice may be extraordinary difficult to explain.

Posner (2008), in contrast, argues that the administrative advances of strict liability are more limited than has generally be recognized. Wagner (1995) also offers a defense of the impossibility defense. He points out that this defense assigns some risk of loss to the promisee which may alleviate the effects from over-reliance.

This brings me to a recent legal debate on the issue in Germany. The 2002 reform has introduced a commercial impracticability doctrine explicitly into the obligation law. ${ }^{1}$ To admit the defense, the promisor must have sufficiently invested in precaution. In addition, his costs of performance must be "disproportionate" to the promisee's benefits.

Nevertheless, the formulation of the provision remains vague. Worse, as Ackermann (2002) has pointed out, a literal interpretation of the provision

\footnotetext{
${ }^{1}$ See German Civil Code $\S 275$ II BGB. I am grateful to Johannes Köndgen for drawing my attention to the German debate on the impracticability doctrine.
} 
would, in terms of the promisor's payoff, be inconsistent with the less controversial physical impossibility defense. ${ }^{2}$ He argues in favor of a more consistent interpretation according to which the impracticability defense should be admitted whenever the promisor's costs of performing exceed the price as specified in the contract. Put differently, while Posner (2008) requires performance to be excused when performance turns out to be inefficient, ${ }^{3}$ Ackermann argues in favor of the excuse being admitted if performance fails to be profitable.

The present paper investigates reliance and precaution incentives that are generated under the two interpretations of the impracticability defense. It is shown that the rule based on the profitability interpretation outperforms, in terms of investment incentives, the rule based on the efficiency interpretation. As it turns out, expectation damages combined with the impracticability defense based on non-profitability of performance allow to restore efficient incentives quite generally.

The main findings of the paper and its organization are as follows. Before the general notation is introduced in section 3, an illustrative numerical example is discussed in section 2. The example exhibits several properties that are noteworthy. The impracticability defense if based on inefficiency of performance generates efficient investment incentives but only if costs of performance are distributed discretely. Reliance incentives may well be distorted if costs of performance are distributed continuously. Reliance incentives are also distorted if the factor by which costs must exceed benefits to admit the defense is higher than one. If, alternatively, the defense is based on nonprofitability of performance then efficient investment incentives are restored. These properties of the numerical example will be shown to extend to the general model as introduced in section 3 .

Section 4 provides a tool that derives incentive properties from compensatory properties of legal regimes. The shape of the payoff of one party as a function of the other party's decision allows to conclude whether the other party has efficient, excessive or insufficient incentives.

In section 5, the legal regime is examined where the promisor owes expec-

\footnotetext{
${ }^{2}$ German Civil Code $§ 275$ I BGB.

${ }^{3}$ In the German discussion, Köndgen (2008) also argues in favor of an impracticability defense based on inefficiency.
} 
tation damages to the promisee unless the promisor has sufficiently invested into precautions but, nonetheless, performance fails to be efficient. Quite generally, this regime provides excessive reliance incentives. If, in contrast, the impracticability defense is admitted provided that the promisor has invested sufficiently into precautions but, nonetheless, costs of performance exceed the price as specified in the contract then this legal regime generates efficient investment incentives for both parties as will be shown in section 6 .

In section 7, the legal regime originally examined by Sykes (1990) is revisited. While the scheme generates efficient reliance incentives it requires courts to determine the benefit from efficient reliances even if the promisee actually has invested at an inefficient level. In section 8, specific performance instead of expectation damages as breach remedy is combined with the impracticability defense based on non-profitability of performance. In terms of informational requirements, this legal regime would seem quite attractive. This regime is shown to generate efficient reliance incentives but may distort precaution incentives, at least under uncertain benefits from performance. Section 9 concludes.

\section{Numerical example}

Before introducing the general notation and establishing the results of the paper, let me illustrate some of the findings by the following numerical example adapted from Posner (2008). By choosing the level of reliances, the buyer decides on the benefit $V(r)=r \in[0,2]$ which she will enjoy from performance. Her reliance expenditures amount to $H(r)=r^{2} / 4$. The seller's costs of performance are, ex ante, uncertain and will be either low $c_{L}=0$ or high $c_{H}=3$. Precautions affect the probability $s \in[0,1]$ with which his costs of performance will be low. Precaution expenditures amount to $K(s)=2 s^{4}$. Notice, ex post, it is efficient to perform if and only if costs of performance happen to be low. The expected social surplus amounts to $W(r, s)=s \cdot r-H(r)-K(s)$ and attains its maximum at $r^{*}=1$ and $s^{*}=1 / 2$.

To begin with, suppose the buyer is awarded expectation damages whenever the seller fails to perform. Then the buyer's expected payoff amounts to $U(r)=V(r)-H(r)$ and is independent of the seller's precautions. This payoff attains its maximum in excess of efficient reliances at $r=2>r^{*}$, well 
in line with the familiar over-reliance result.

Under Posner's negligence regime, the seller owes expectation damages for nonperformance if either he fails to perform in spite of his costs being low or if his costs are high but he has failed to invest sufficiently into precautions.

Anticipating this regime, parties have signed a fixed price contract that specifies price $p=V\left(r^{*}\right)=1$ for performance. In fact, as Proposition 1 below will establish, this price is the only candidate for generating efficient investment incentives. At low reliances where $V(r)<p$, the seller would never invoke the impracticability defense but, instead, would either perform or, at high performance costs, would pay expectation damages. Only at high reliances where $p \leq V(r)$, he will invoke the defense provided that costs of performance also happen to be high.

Suppose, by deciding $s=s^{*}=1 / 2$, the seller has actually invested sufficiently into precautions. Then the buyer's expected payoff amounts to

$$
U\left(r, s^{*}\right)=\left\{\begin{array}{lll}
V(r)-p-H(r) & \text { if } & V(r)<p \\
s^{*} \cdot(V(r)-p)-H(r) & \text { if } & p \leq V(r)
\end{array}\right.
$$

and is easily seen to attain its maximum at efficient reliances $r=r^{*}$ indeed. Moreover, if the buyer invests efficiently the seller becomes residual claimant and, hence, has efficient precaution incentives as well. In sum, the regime provides efficient investment incentives for both parties as claimed by Posner.

Efficient incentives, however, will be distorted in two ways. First, legal practice may admit the impracticability defense only if net costs of performance $c-p$ exceed net benefits $V(r)-p$ by a larger margin $\lambda>1$. For illustration, take $\lambda=5 / 2$. Then, even if benefits are at their maximum $V(2)=2$ and costs of performance happen to be high, the defense would be denied and, for that reason, it would be in the buyer's interest to overinvest into reliances. In other words, by insisting on a margin $\lambda>1$, legal practice may distort reliance incentives which, otherwise, would be efficient.

Second, distortions also arise if costs of performance are continuously distributed what seems to be a natural extension of Posner's binary setting. To illustrate the point, let costs of performance be uniformly distributed in the interval $c \in[0,2] .{ }^{4}$ The buyer still chooses $V(r)=r$ from the interval $[0,2]$ though at reliance expenditures $H(r)=r^{3} / 12+r^{2} / 8$. The expected

\footnotetext{
${ }^{4}$ For simplicity, precaution investments are not considered in this version of the model.
} 
social surplus amounts to

$$
W(r)=\frac{1}{2} \int_{0}^{r}(V(r)-c) \cdot d c-H(r)=\frac{r^{2}}{4}-\frac{r^{3}}{12}-\frac{r^{2}}{8}
$$

and attains its maximum at $r^{*}=1$.

Again, as will be shown in Proposition 1, the only candidate of a fixed price contract generating efficient reliance incentives would be to specify the price $p=V\left(r^{*}\right)=1$. Yet, in the above example, reliance incentives turn out to be distorted even if this price was chosen. In fact, for reliances in the range $p=1 \leq V(r)=r$, the seller invokes the defense as soon as it is admitted, i.e. as soon as performance would be inefficient. In this range, the buyer's expected payoff amounts to

$$
U(r)=\frac{1}{2} \int_{0}^{r}(V(r)-p) \cdot d c-H(r)=\frac{r \cdot(r-1)}{2}-\frac{r^{3}}{12}-\frac{r^{2}}{8}
$$

such that her marginal payoff amounts to

$$
\frac{d U(r)}{d r}=-\frac{r^{2}-3 r+2}{4}
$$

and is easily seen to be non-negative in the whole range $[1,2]$. It follows that the buyer is facing excessive reliance incentives as claimed.

While, in the above setting, the choice of the cost function is crucial to jeopardize efficient incentives, Proposition 2 will establish that reliance incentives are distorted in general if, not only, costs of performance but also benefits are uncertain from the ex ante perspective.

To conclude this section, reliance incentives are examined that would result from admitting the impracticability defense as soon as performance fails to be profitable, i.e. as soon as $c>p=1$ holds. Recall, the interpretation based on non-profitability of performance, has been proposed by Ackermann (2002).

Again, the seller will invoke the defense only if reliances are from the range $p<V(r)$. Yet, if costs of performance happen to lie in between, $p<c<V(r)$, the buyer may threaten to invoke the defense in spite of the fact that performance would still be efficient. Following Rogerson (1984), parties are assumed to renegotiate under such circumstances with the buyer obtaining the fixed share $0<\alpha<1$ of the renegotiation surplus. Including renegotiations, the buyer's expected payoff amounts to

$$
U(r)=\frac{1}{2} \int_{0}^{p}(V(r)-p) \cdot d c+\frac{\alpha}{2} \cdot \int_{p}^{r}(V(r)-c) \cdot d c-H(r)
$$




$$
=(r-p) \cdot \frac{p}{2}+\frac{\alpha}{4}\left(r^{2}-2 \cdot r \cdot p+p^{2}\right)-\frac{r^{3}}{12}-\frac{r^{2}}{8}
$$

which attains its maximum at the lower end of the range $p=1 \leq V(r)=r$. Efficient incentives are restored indeed. Propositions 3 and 4 will establish that efficient incentives would be generated quite generally, not just in the above example, if the impracticability defense were admitted upon nonprofitability of performance.

\section{The model}

The main findings of the paper are established within the following model of reliance and precaution investments. The promisee, referred to as buyer, decides on reliance investments $r \in R$ whereas the promisor, referred to as seller, decides on precaution investments $s \in S$. Ex post, he also decides on performance. For mathematical convenience, the sets $R$ and $S$ are assumed to be compact intervals of the real line.

If the seller fails to perform his alternative (expected) costs amount to $C^{n}(s)$ and the buyer's alternative (expected) benefits amount to $V^{n}(r)$. The (additional) costs and benefits from performance are denoted by $c$ and $v$, respectively. Costs $c$ are assumed to be distributed with density $f(c, s)$ and cumulative distribution function $F(c, s)$ over the interval $[0, B]$.

As for benefits $v$, two cases are distinguished. In the case of deterministic benefits, benefits are assumed to be a continuous function $v=V(r) \geq 0$ of reliance investments with maximum $A=\max _{r \in R} V(r)$ whereas, in the case of uncertain benefits, benefits $v$ are assumed to be distributed with density $g(v, r)$ and cumulative distribution function $G(v, r)$ over the interval $[0, A]$. For later use, let $M=\max [A, B]$ denote the maximum of the two upper ends.

At benefit $v$ and precaution investments $s$, the expected (additional) social surplus amounts to

$$
\sigma(v, s)=\int_{0}^{v}(v-c) \cdot f(c, s) \cdot d c=\int_{0}^{v} F(c, s) \cdot d c
$$

with partial derivative $\sigma_{v}=F(v, s)$.

Under deterministic benefits, the expected social surplus amounts to

$$
W(r, s)=\sigma(V(r), s)-H(r)-K(s)
$$


where $H(r)=r-V^{n}(r)$ denotes reliance expenditures net of alternative benefits of the buyer and $K(s)=s+C^{n}(s)$ denotes precaution expenditures plus alternative costs of the seller. The functions $H(r)$ and $K(s)$ are referred to as cost functions. Notice, for later reference, the partial derivatives of social surplus are

$$
W_{s}=\sigma_{s}(V(r), s)-K_{s}(s) \text { and } W_{r}=F(V(r), s) \cdot V_{r}(r)-H_{r}(r) .
$$

Under uncertain benefits, the expected social surplus amounts to

$$
\begin{aligned}
W(r, s) & =\int_{0}^{M} \sigma(v, s) \cdot g(v, r) \cdot d v-H(r)-K(s) \\
& =\int_{0}^{M}[1-G(v, r)] \cdot F(v, s) \cdot d v-H(r)-K(s)
\end{aligned}
$$

with partial derivative

$$
W_{r}(r, s)=-\int_{0}^{M} F(v, s) \cdot G_{r}(v, r) \cdot d v-H_{r}(r) .
$$

The first best solution maximizes social surplus and is denoted by

$$
\left(r^{*}, s^{*}\right) \in \arg \max _{(r, s) \in R \times S} W(r, s) .
$$

Use of the following assumptions will be made repeatedly.

\section{Assumption C:}

If $c \in(0, B)$ then $f(c, s)>0$ and $F_{s}(c, s)>0$.

Higher precaution investments are shifting the distribution of the costs of performance in the direction of first order stochastic dominance. Moreover, under deterministic benefits, assumption D whereas, under uncertain benefits, assumption $\mathrm{U}$ is assumed to hold.

\section{Assumption D:}

Marginal benefits from reliance investments are positive, i.e. $V_{r}(r)>0$.

\section{Assumption U:}

$$
\text { If } v \in(0, A) \text { then } g(v, r)>0 \text { and } G_{r}(v, r)<0 \text {. }
$$

Higher reliance investments increase the benefit from performance in the sense of first order stochastic dominance. The above assumptions are standard and need no comment.

The setting allows to define the exact conditions under which impracticability defenses are admitted. As a necessary condition for admitting the 
defense, the seller must not be responsible for the impracticability of performance in the sense that he has sufficiently invested in precaution. The precaution standard, a parameter of the legal regime, is denoted by $s^{n}$.

Suppose the contract has specified $p$ as the (fixed) price for performance ${ }^{5}$ and, by choosing $s \geq s^{n}$, the seller has actually met the precaution standard. Under the interpretation based on ex post efficiency, the defense is admitted if the costs of performance exceed the benefits, i.e. if $v<c .{ }^{6}$ Under the interpretation based on ex post profitability, the defense is admitted as soon as the costs of performance exceed the price, i.e. if $p<c$.

The present paper compares the investment incentives that are generated under the two different interpretations of the defense.

\section{Compensation and incentives}

Cooter (1985) has identified two distinct goals for adopting allocative cost rules: the equity goal of compensating victims and the efficiency goal of minimizing costs to society as a whole. Yet, no painful trade-off between compensation and incentives need arise. Rather, as pointed out by Cooter, it may be the very requirement to compensate which generates correct incentives. The present paper systematically exploits this fact.

The legal regime in place affects the distribution of the social surplus $W(r, s)$ among the two parties. For a given regime, let $U(r, s)$ denote the buyer's expected payoff. By assumption, third parties are not affected such that the seller's payoff amounts to the residual $\Delta(r, s)=W(r, s)-U(r, s)$.

The legal regime generates efficient reliance incentives if

$$
r^{*} \in \arg \max _{r} U\left(r, s^{*}\right)
$$

It generates weakly excessive reliance incentives if there exists

$$
r_{A} \in \arg \max _{r} U\left(r, s^{*}\right)
$$

\footnotetext{
${ }^{5}$ In addition, up-front payments may be needed to shift the ex ante distribution of surplus between parties. Such payments do not affect incentives and, for that reason, are omitted in the formulas.

${ }^{6}$ As the numerical example has shown, from the perspective of investment incentives, it would be detrimental to insist on a larger margin. For that reason, higher margins are not examined by the present paper.
} 
such that $r^{*} \leq r_{A}$. It generates excessive reliance incentives if, for

$$
r_{A} \in \arg \max _{r} U\left(r, s^{*}\right)
$$

it follows that $r^{*}<r_{A}$. Weakly insufficient and insufficient reliance incentives as well as the corresponding precaution incentives are defined along the same lines.

The following two lemmata summarize how incentives of one party are generated by the requirement to compensate the other party.

Lemma 1 (a) If the buyer is fully compensated for any deviation by the seller from efficient precautions, i.e. if $U\left(r^{*}, s^{*}\right) \leq U\left(r^{*}, s\right)$ holds for all $s \in S$, then the seller has efficient precaution incentives.

(b) If the buyer is compensated but only for insufficient precautions, i.e. if $U\left(r^{*}, s^{*}\right) \leq U\left(r^{*}, s\right)$ holds for all $s \leq s^{*}$, then the seller has weakly excessive precaution incentives.

(c) If the buyer is compensated but only for excessive precautions, i.e. if $U\left(r^{*}, s^{*}\right) \leq U\left(r^{*}, s\right)$ holds for all $s \geq s^{*}$ then the seller has weakly insufficient precaution incentives. If, in addition, $U_{s}\left(r^{*}, s^{*}\right)>0$ then the seller has insufficient reliance incentives.

Lemma 2 (a) If the seller is fully compensated for any deviation by the buyer from efficient reliances, i.e. if $\Delta\left(r^{*}, s^{*}\right) \leq \Delta\left(r, s^{*}\right)$ holds for all $r \in R$, then the buyer has efficient reliance incentives.

(b) If the seller is compensated but only for insufficient reliances, i.e. if $\Delta\left(r^{*}, s^{*}\right) \leq \Delta\left(r, s^{*}\right)$ holds for all $r \leq r^{*}$, then the buyer has weakly excessive reliance incentives. If, in addition, $\Delta_{r}\left(r^{*}, s^{*}\right)<0$ then the buyer has excessive reliance incentives.

(c) If the seller is compensated but only for excessive reliances, i.e. if $\Delta\left(r^{*}, s^{*}\right) \leq \Delta\left(r, s^{*}\right)$ holds for all $r \geq r^{*}$ and if $\Delta_{r}\left(r^{*}, s^{*}\right)>0$ then the buyer has insufficient reliance incentives.

Proof. Lemma 1 can be established as follows.

(a) Since $\Delta\left(r^{*}, s\right)=W\left(r^{*}, s\right)-U\left(r^{*}, s\right) \leq W\left(r^{*}, s^{*}\right)-U\left(r^{*}, s^{*}\right)=\Delta\left(r^{*}, s^{*}\right)$ holds for any $s$, it follows that the seller has efficient precaution incentives indeed. 
(b) In this case, $\Delta\left(r^{*}, s\right) \leq \Delta\left(r^{*}, s^{*}\right)$ holds for any $s \leq s^{*}$ and, hence, the seller's best response can, without loss of generality, be searched for in the range $s^{*} \leq s$. Claim (b) is established.

(c) Without loss of generality, the seller's best response can be searched for in the range $s \leq s^{*}$. Moreover, if the derivative $U_{s}\left(r^{*}, s^{*}\right)>0$ is strictly positive then the derivative $\Delta_{s}\left(r^{*}, s^{*}\right)<0$ must be strictly negative. Therefore, by investing marginally below efficient precautions $s^{*}$, the seller can strictly increase his payoff. This means that he has insufficient precaution incentives as claimed. Lemma 1 is established.

Lemma 2 can be established along similar lines. Details are omitted.

Notice, if each party is fully compensated for deviations by the other party then the profile $\left(r^{*}, s^{*}\right)$ of efficient investments is a saddle point of both parties' payoff functions. As a consequence, the profile must, not only, be a Nash equilibrium but, if several Nash equilibria exist, they must all be payoff equivalent. ${ }^{7}$

\section{Performance excused if inefficient}

In the present section, the following legal regime is examined. If the seller has met the precaution standard $s^{n}$ but fails to perform then he is excused if performance happens to be inefficient, i.e. if $v<c$. In all other cases, he owes expectation damages to the buyer for failing to perform.

To begin with, suppose the buyer's benefit is lower than the price for performance, i.e. $v<p$. Then the seller either performs or pays expectation damages and, hence, the impracticability defense is effectless in this range of benefits. The buyer's payoff amounts to $\phi(v)-H(r)$ where $\phi(v)=v-p$.

If the costs are in the range $p \leq v$ but the seller was negligent by choosing insufficient precautions $s<s^{n}$, the buyer's payoff still amounts to $\phi(v)-$ $H(r)$. If, however, by choosing sufficient precautions $s \geq s^{n}$, the seller is excused for nonperformance provided that $v<c$ holds then the buyer's payoff amounts to $\psi(v, s)-H(r)$ where $\psi(v, s)=F(v, s) \cdot(v-p)$.

Notice, at $v=p$, it holds that $\phi(p)=\psi(p, s)=0$ and, hence, the buyer's payoff is continuous as a function of benefit $v$. Her payoff is also continuous

\footnotetext{
${ }^{7}$ For a more elaborate discussion of this saddle point property, the reader may wish to consult Schweizer (2005).
} 
as a function of precautions except possibly at $s=s^{n}$ where it may jump downwards.

If the buyer's benefit is a deterministic function of reliances, $v=V(r)$, then her expected payoff amounts to $U(r, s)=\phi(V(r))-H(r)$ except for the case where the seller has met the negligence standard, $s^{n} \leq s$, and the price for performance is less than the benefit, $p<V(r)$. In the latter case, the buyer's expected payoff amounts to $U(r, s)=\psi(V(r), s)-H(r)$. Lemma 1 and Lemma 2 can now be used to establish the following proposition.

Proposition 1 (deterministic benefits)

(a) If $V\left(r^{*}\right) \leq p$ then the seller has efficient precaution incentives.

(b) If $p<V\left(r^{*}\right)$ then the seller has efficient (weakly excessive, and insufficient) precaution incentives if $s^{n}=s^{*}\left(s^{*}<s^{n}\right.$, and $s^{n}<s^{*}$, respectively).

(c) If $s^{n} \leq s^{*}$ then the buyer has excessive reliance incentives unless $p=V\left(r^{*}\right)$. If $p=V\left(r^{*}\right)$ then she has weakly excessive reliance incentives.

(d) If $s^{*}<s^{n}$ then the buyer has excessive reliance incentives.

Proof. (a) If $V\left(r^{*}\right) \leq p$ then $U_{s}\left(r^{*}, s\right)=0$ and, hence, the seller has efficient precaution incentives as follows from Lemma 1 (a). He, in fact, is residual claimant.

(b) If $p<V\left(r^{*}\right)$ then $U_{s}\left(r^{*}, s\right)=0$ for $s<s^{n}$ and

$$
U_{s}\left(r^{*}, s\right)=\psi_{s}\left(V\left(r^{*}\right), s\right)=F_{s}\left(V\left(r^{*}\right), s\right) \cdot\left(V\left(r^{*}\right)-p\right)>0
$$

for $s^{n} \leq s$. Moreover, since

$$
\lim _{s \uparrow s^{n}} U\left(r^{*}, s\right) \geq \lim _{s \downarrow s^{n}} U\left(r^{*}, s\right),
$$

the seller has efficient precaution incentives if $s^{n}=s^{*}$ as follows from Lemma 1 (a). He has weakly excessive precaution incentives if $s^{*}<s^{n}$ as follows from Lemma 1 (b). He has insufficient precaution incentives if $s^{n}<s^{*}$ as follows from Lemma 1 (c).

(c) If $s^{n} \leq s^{*}$ then

$$
\Delta_{r}\left(r, s^{*}\right)= \begin{cases}-\left(1-F\left(V(r), s^{*}\right)\right) \cdot V_{r}(r)<0 & \text { if } \quad V(r)<p \\ 0 & \text { if } \quad V(r)=p \\ -f\left(V(r), s^{*}\right) \cdot(V(r)-p)<0 & \text { if } \quad p<V(r)\end{cases}
$$

and claim (c) follows from Lemma 2 (b). 
(d) If, finally, $s^{*}<s^{n}$ then $\Delta_{r}\left(r, s^{*}\right)=-\left(1-F\left(V(r), s^{*}\right)\right) \cdot V_{r}(r)<0$ and claim (d) also follows from Lemma 2 (b).

The main conclusion from Proposition 1 is as follows. To generate efficient investment incentives for both parties, the only candidate is $p=V\left(r^{*}\right)$ and $s^{n} \leq s^{*}$. In words, the (fixed price) contract must specify the benefit under efficient reliances as price for performance and the negligence standard must be low enough such that efficient precautions meet the standard. ${ }^{8}$ Yet, the only candidate may still fail to provide efficient reliance incentives as the numerical example has shown.

If the buyer's benefit is uncertain, being distributed in the interval $c \in$ $[0, A]$ with density $g(v, r)$ and cumulative distributive function $G(v, r)$, then the buyer's expected payoff is as follows. In the range $s<s^{n}$, her expected payoff amounts to

$$
\begin{aligned}
U(r, s) & =\int_{0}^{M}(v-p) \cdot g(v, r) \cdot d v-H(r) \\
& =M-\int_{0}^{M} G(v, r) \cdot d v-p-H(r)
\end{aligned}
$$

whereas, in the range $s^{n} \leq s$, it amounts to

$$
\begin{aligned}
U(r, s) & =\int_{0}^{p}(v-p) \cdot g(v, r) \cdot d v+\int_{p}^{M} \psi(v, s) \cdot g(v, r) \cdot d v-H(r) \\
& =-\int_{0}^{p} G(v, r) \cdot d v+\psi(M, s)-\int_{p}^{M} \psi_{v}(v, s) \cdot G(v, r) \cdot d v-H(r) .
\end{aligned}
$$

Lemma 1 and Lemma 2 can now be used to establish the following proposition.

Proposition 2 (uncertain benefits)

(a) If $s^{n}=s^{*}$ (or $s^{*}<s^{n}$, or $\left.s^{n}<s^{*}\right)$ then the seller has efficient (or weakly excessive, or insufficient, respectively) precaution incentives.

(b) The buyer always has excessive reliance incentives.

Proof. (a) In the range $s<s^{n}$, it holds that $U_{s}\left(r^{*}, s\right)=0$, whereas in the range $s^{n}<s$, it holds that

$$
U_{s}\left(r^{*}, s\right)=\int_{p}^{M} \psi_{s}(v, s) \cdot g(v, r) \cdot d v>0
$$

\footnotetext{
${ }^{8} \mathrm{Up}$-front payments are possibly needed to redistribute the surplus at the contracting stage.
} 
Notice further that

$$
\lim _{s \uparrow s^{n}} U\left(r^{*}, s\right) \geq \lim _{s \downarrow s^{n}} U\left(r^{*}, s\right) .
$$

Claim (a) then easily follows from Lemma 1 (a) - (c).

(b) Since

$$
\begin{aligned}
& \Delta_{r}\left(r, s^{*}\right) \\
= & -\int_{0}^{M} F(v, s) \cdot G_{r}(v, r) \cdot d v+\int_{0}^{p} G_{r}(v, r) \cdot d v+\int_{p}^{M} \psi_{v}(v, s) \cdot G_{r}(v, r) \cdot d v \\
= & \int_{0}^{p}[1-F(v, s)] \cdot G_{r}(v, r) \cdot d v-\int_{p}^{M}\left(F(v, s)-\psi_{v}(v, s)\right) \cdot G_{r}(v, r) \cdot d v<0,
\end{aligned}
$$

it follows from Lemma 2 (b) that the buyer has excessive reliance incentives indeed.

The main conclusion from Proposition 2 is that, under uncertain benefits, the legal regime fails to provide efficient reliance incentives. This negative result holds if performance is excused whenever performance happens to be inefficient. Under the alternative interpretation of the impracticability doctrine based on non-profitability, however, efficient reliance incentives would be restored as is shown in the next section.

\section{Performance excused if not profitable}

In the present section, the following alternative legal regime is examined. If the seller has met the precaution standard $s^{n}$ but fails to perform then he is excused if performance fails to be profitable, i.e. if $p<c$. In all other cases, he owes expectation damages to the buyer if he fails to perform.

To begin with, suppose the buyer's benefit is lower than the price for performance, $v<p$. In this range, the seller will never invoke the impracticability defense and, hence, the buyer's payoff amounts to $\phi(v)-H(r)$ where $\phi(v)=v-p$.

If the costs are in the range $p \leq v$ but the seller was negligent by choosing insufficient precautions, $s<s^{n}$, the buyer's payoff also amounts to $\phi(v)-$ $H(r)$. If, however, by choosing sufficient precautions, $s \geq s^{n}$, the seller is excused for nonperformance provided that $p<c$ holds. The seller may threaten to invoke the defense even in cases where it would be efficient to perform. In such cases, parties are assumed to renegotiate and to share the renegotiation surplus in fixed proportions $\alpha$ for the buyer and $\beta=1-\alpha$ for 
the seller. Taking such renegotiations into account, in the range $s \geq s^{n}$, the buyer's payoff amounts to $\psi(v, s)-H(r)$ where

$$
\begin{aligned}
\psi(v, s) & =F(p, s) \cdot(v-p)+\alpha \cdot \int_{p}^{v}(v-c) \cdot f(c, s) \cdot d c \\
& =\beta \cdot F(p, s) \cdot(v-p)+\alpha \cdot \int_{p}^{v} F(c, s) \cdot d c .
\end{aligned}
$$

Notice, at $v=p$, it holds again that $\phi(p)=\psi(p, s)=0$ and, hence, the buyer's payoff is continuous as a function of benefit $v$. Her payoff is also continuous as a function of precautions except possibly at $s=s^{n}$ where it may jump downwards.

If the buyer's benefit is a deterministic function of reliances, $v=V(r)$, then her expected payoff amounts to $U(r, s)=\phi(V(r))-H(r)$ except for the case where the seller has met the negligence standard, $s^{n} \leq s$, and the price for performance is less than the benefit, $p<V(r)$. In the latter case, the buyer's expected payoff amounts to $U(r, s)=\psi(V(r), s)-H(r)$. Lemma 1 and Lemma 2 are now used to establish the following proposition.

Proposition 3 (deterministic benefits)

(a) If $V\left(r^{*}\right) \leq p$ then the seller has efficient precaution incentives.

(b) If $p<V\left(r^{*}\right)$ then the seller has efficient (weakly excessive, or insufficient) precaution incentives if $s^{n}=s^{*}\left(s^{*}<s^{n}\right.$, or $s^{n}<s^{*}$, respectively) holds.

(c) If $s^{n} \leq s^{*}$ then the buyer has efficient (excessive, or insufficient) reliance incentives if $p=V\left(r^{*}\right)\left(V\left(r^{*}\right)<p\right.$, or $p<V\left(r^{*}\right)$, respectively) holds.

(d) If $s^{*}<s^{n}$ then the buyer has excessive reliance incentives.

Proof. The proofs of (a), (b) and (d) are similar to the corresponding proofs for Proposition 1 and, for that reason, are omitted here. To establish (c), the partial derivative of the seller's expected payoff with respect to the buyer's reliance investments must be determined. In the range $V(r)<p$, this derivative is the same as in Proposition 1 and, hence, it holds that $\Delta_{r}\left(r, s^{*}\right)<0$ in this range of reliances.

In the range $p \leq V(r)$, the derivative amounts to

$$
\begin{aligned}
\Delta_{r}\left(r, s^{*}\right) & =\left(F\left(V(r), s^{*}\right)-\psi_{v}\left(V(r), s^{*}\right)\right) \cdot V_{r}(r) \\
& =\beta \cdot\left(F\left(V(r), s^{*}\right)-F\left(p, s^{*}\right)\right) \cdot V_{r}(r)
\end{aligned}
$$


and, hence, must be positive if $p<V(r)$. The first claim of (c) follows from Lemma 2 (a), the second claim from Lemma 2 (b) and the third claim from Lemma 2 (c).

The main conclusion from Proposition 3 is that the legal regime where the impracticability defense rests on non-profitability (in contrast to where it rests on inefficiency) provides efficient incentives for both parties. To generate efficient incentives, the contract must specify price $p=V\left(r^{*}\right)$ for performance and the negligence standard must not exceed the efficient level of precautions.

If the buyer's benefit is uncertain, being distributed in the interval $c \in$ $[0, A]$ with density $g(v, r)$ and cumulative distributive function $G(v, r)$ then the buyer's expected payoff is as follows. In the range $s<s^{n}$, her expected payoff still amounts to

$$
\begin{aligned}
U(r, s) & =\int_{0}^{M}(v-p) \cdot g(v, r) \cdot d v-H(r) \\
& =M-\int_{0}^{M} G(v, r) \cdot d v-p-H(r)
\end{aligned}
$$

whereas, in the range $s^{n} \leq s$, it amounts to

$$
\begin{aligned}
& U(r, s) \\
= & \int_{0}^{p}(v-p) \cdot g(v, r) \cdot d v+\int_{p}^{M} \psi(v, s) \cdot g(v, r) \cdot d v-H(r) \\
= & -\int_{0}^{p} G(v, r) \cdot d v+\psi(M, s)- \\
& -\int_{p}^{M}(\beta \cdot F(p, s)+\alpha \cdot F(v, s)) \cdot G(v, r) \cdot d v-H(r) .
\end{aligned}
$$

To establish part (b) of the next proposition, an additional assumption is needed. The buyer's cost function $H(r)$ must exhibit increasing marginal costs, $H_{r r}(r) \geq 0$, and the cumulative distribution function governing uncertain benefits must also be concave in reliances, $G_{r r}(v, r) \geq 0$. It follows from this assumption and the above equation that $U_{r r}(r, s) \leq 0$ and, hence, the buyer's expected payoff is a concave function of reliances.

Proposition 4 (uncertain benefits)

(a) If $s^{*}=s^{n}\left(s^{*}<s^{n}\right.$, or $\left.s^{n}<s^{*}\right)$ then the seller has efficient (weakly excessive, or insufficient, respectively) precaution incentives.

(b) Suppose the buyer's cost function $H$ and the cumulative distribution function $G$ are concave in reliances $r$. If $s^{n} \leq s^{*}$ then there exists a unique 
price $p^{*}$ to be specified for performance such that the buyer has efficient reliance incentives. If $p<p^{*}\left(p>p^{*}\right)$ then the buyer has insufficient (excessive) reliance incentives.

(c) If $s^{*}<s^{n}$ then the buyer has excessive reliance incentives.

Proof. (a) If $s<s^{n}$ then $U_{s}\left(r^{*}, s\right)=0$ whereas if $s^{n}<s$ then $U_{s}\left(r^{*}, s\right)=$ $\int_{p}^{M} \psi_{s}(v, s) \cdot g(v, r) \cdot d v>0$. Since

$$
\lim _{s \uparrow s^{n}} U\left(r^{*}, s\right) \geq \lim _{s \downarrow s^{n}} U\left(r^{*}, s\right)
$$

claim (a) immediately follows from Lemma 1.

(b) If $s^{n} \leq s^{*}$ then the buyer's expected payoff $U\left(r, s^{*}\right)$ is a concave function of reliances. Moreover, since

$$
\begin{aligned}
& \Delta_{r}\left(r, s^{*}\right) \\
= & -\int_{0}^{M} F(v, s) \cdot G_{r}(v, r) \cdot d v+\int_{0}^{p} G_{r}(v, r) \cdot d v+ \\
& +\int_{p}^{M}\left(\beta \cdot F\left(p, s^{*}\right)+\alpha \cdot F\left(v, s^{*}\right)\right) \cdot G_{r}(v, r) \cdot d v \\
= & \int_{0}^{p}(1-F(v, s)) \cdot G_{r}(v, r) \cdot d v-\int_{p}^{M}\left(F\left(v, s^{*}\right)-F\left(p, s^{*}\right)\right) \cdot G_{r}(v, r) \cdot d v
\end{aligned}
$$

it follows that $\Delta_{r}\left(r^{*}, s^{*}\right)>0(<0)$ if $p=0(p=M)$ and, hence, that a unique price $p^{*}$ must exist at which $\Delta_{r}\left(r^{*}, s^{*}\right)=0$ holds. It follows that, at this price, $U_{r}\left(r^{*}, s^{*}\right)=W_{r}\left(r^{*}, s^{*}\right)-\Delta_{r}\left(r^{*}, s^{*}\right)=0$ and, hence, the buyer has efficient reliance incentives if parties have specified price $p^{*}$ in their contract.

The remaining claims of (b) follow from the fact that

$$
\frac{\partial U_{r}\left(r^{*}, s^{*}\right)}{\partial p}=-\left(1-F\left(p, s^{*}\right)\right) \cdot G_{r}\left(p, r^{*}\right)>0 .
$$

(c) If $s^{*}<s^{n}$ then

$$
\Delta_{r}\left(r, s^{*}\right)=\int_{0}^{M}\left(1-F\left(v, s^{*}\right)\right) \cdot G_{r}(v, r) \cdot d v<0
$$

for all $r$ and, hence, the buyer has excessive reliance incentives as follows from Lemma 2 (b).

The main conclusion from the above proposition is that the legal regime where the impracticability defense rests on non-profitability of performance generates efficient investment incentives for both parties even under uncertain benefits. For this result to hold, parties must have specified the appropriate price $p=p^{*}$ for performance in their contract and courts must impose the correct negligence standard $s^{n}=s^{*}$ for precautions. 


\section{The legal regime examined by Sykes}

In this section, the above findings are compared with the legal regime examined by Sykes (1990). Sykes deals with the case of deterministic benefits, $v=V(r)$, only. Moreover, precaution investments are not taken into account such that density $f(c)$ and cumulative distribution functions $F(c)$ are exogenously given.

The law (courts?) is assumed to choose a parameter $T$ which serves as a threshold in the following sense. If the seller's costs of performance exceed the threshold, $T<c$, and the seller does not perform then nonperformance is excused. Otherwise the seller owes expectation damages to the buyer (if he does not perform).

The buyer's payoff is as follows. If $c \leq T$ then the defense is denied and, hence, the buyer's payoff amounts to $\phi(v)-H(r)$ where $\phi(v)=v-p$.

If $T<c$ several subcases must be distinguished. (1) If $v<p$ then the seller does never invoke the defense but rather performs or pays expectation damages. In this case, the buyer's payoff also amounts to $\phi(v)-H(r)$. (2a) If $p \leq v$ and $c<p$ the seller prefers to perform but if performance happens to be inefficient renegotiations take place. In this case, the buyer's expected payoff amounts to $v-p+\alpha \cdot \max [c-v, 0]$. (2b) If $p \leq v$ but $p \leq c$ then the seller invokes the defense. If performance remains to be efficient, renegotiations take place. In this case, the buyer's expected payoff amounts to $\alpha \cdot \max [v-c, 0]$. For Sykes' regime, the following proposition can be established.

Proposition 5 (a) Suppose $p \leq T$. Then the buyer has efficient (excessive, and insufficient) reliance incentives if $T=V\left(r^{*}\right)\left(V\left(r^{*}\right)<T\right.$, and $T<$ $V\left(r^{*}\right)$, respectively).

(b) Suppose $T<p$. Then the buyer has efficient (excessive, and insufficient) reliance incentives if $\left(V\left(r^{*}\right)<p\right.$, and $p<V\left(r^{*}\right)$, respectively).

Proof. (a) If $v<p$ then $\Delta_{v}=-(1-F(v))<0$. If $p \leq v<T$ then $\Delta_{v}=F(v)-F(T)<0$. If, finally, $T<v$ then the buyer's expected payoff amounts to

$$
\begin{aligned}
& F(T) \cdot(v-p)+\alpha \cdot \int_{T}^{v}(v-c) \cdot f(c) \cdot d c-H(r) \\
= & F(T) \cdot(v-p)-F(T) \cdot \alpha \cdot(v-T)+\alpha \cdot \int_{T}^{v} F(c) \cdot d c
\end{aligned}
$$


and, hence, $\Delta_{v}=\beta \cdot(f(v)-F(T))>0$. Taking these signs of the derivatives into account, claim (a) easily follows from Lemma 2.

(b) If $v<T<p$ or if $T \leq v<p$ then $\Delta_{v}=-(1-F(v))<0$ whereas, if $T<p<v$, then the buyer's expected payoff amounts to

$$
\begin{aligned}
& F(p) \cdot(v-p)+\alpha \cdot \int_{p}^{v}(v-c) \cdot f(c) \cdot d c \\
= & \beta \cdot F(p) \cdot(v-p)+\alpha \cdot \int_{p}^{v} F(c) \cdot d c
\end{aligned}
$$

and, hence, $\Delta_{v}=\beta \cdot(F(v)-F(p))>0$. Claim (b) easily follows from Lemma 2 as well.

The main conclusions from the above proposition are as follows. There exist two parameter constellations generating efficient reliance incentives. First, threshold $T=V\left(r^{*}\right)$ provided that the price for performance is in the range $p \leq V\left(r^{*}\right)$. This is the efficient regime discussed by Sykes. Notice, to implement the regime, courts must be able to calculate efficient reliance investments or, at least, the benefits resulting from them.

Second, price $p=V\left(r^{*}\right)$ and the threshold in the range $T<V\left(r^{*}\right)$. This scheme implicitly mimics the interpretation of impracticability based on no-profitability as systematically examined by the present paper. This scheme has the advantage that the (probably better informed) parties have the burden of specifying the appropriate price for performance. Courts need not be able to determine efficient reliance investments.

\section{Specific performance}

The benefit from performance must be verifiable in front of courts in order to award expectation damages correctly. If the benefit cannot be assessed the remedy of specific performance may serve as an attractive alternative. Rogerson (1984) has shown that the over-reliance problem persists if the seller is strictly liable to perform. In the present section, elements of a negligence system are combined with specific performance. More precisely, the following legal regime is examined. If the seller has met the precaution standard $s^{n}$ but fails to perform then he is excused if performance fails to be profitable, i.e. $p<c .^{9}$

\footnotetext{
${ }^{9}$ The analysis of the present section is restricted to the impracticability defense based on non-profitability of performance. If it were based on inefficiency of performance, qual-
} 
To begin with, suppose the seller has invested insufficiently, $s<s^{n}$, such that the impracticability defense will be denied. Imagine that the buyer has already paid the price $p$ before performance was due. If the seller does not perform then the only option left for the buyer is to invoke specific performance and, hence, to end up with payoff $v-p$. Yet, if performance happens to be inefficient, parties are assumed to renegotiate. Taking renegotiations into account, the buyer's expected profit amounts to $\phi(v, s)-H(r)$ where

$$
\begin{aligned}
\phi(v, s) & =v-p+\alpha \cdot \int_{v}^{M}(c-v) \cdot f(c, s) \cdot d c \\
& =v-p+\alpha \cdot \int_{v}^{M}(1-F(c, s)) \cdot d c .
\end{aligned}
$$

If, however, the seller has invested sufficiently, $s^{n} \leq s$, then the impracticability defense is admitted as soon as costs of performance exceed its price, $p<c$. For such precautions, the buyer's expected payoff amounts to $\psi(v, s)-H(r)$ where

$$
\begin{aligned}
\psi(v, s) & =F(p, s) \cdot(v-p)+\alpha \cdot \int_{v}^{p}(c-v) \cdot f(c, s) \cdot d c \\
& =\beta \cdot F(p, s) \cdot(v-p)-\alpha \cdot \int_{v}^{p} F(c, s) \cdot d c .
\end{aligned}
$$

To see why, several cases must be distinguished. (1a) If $v<p$ and $c \leq v$ then the seller performs and performance is efficient leading to the buyer's payoff $v-p$. (1b) If $v<p$ and $v<c \leq p$ then the seller still threatens to perform but renegotiations take place such that the buyer ends up with payoff $v-p+\alpha \cdot(c-v)$. (1c) If $v<p$ and $p<c$ then the defense is invoked and admitted such that the buyer's payoff is zero. Integrating over $c$ leads to the above formula and, hence, the formula is established for the case where $v<p$.

(2a) If $p \leq v$ and $c \leq p$ then the seller performs and performance is efficient such that the buyer's payoff amounts to $v-p$ in this subcase. (2b) If $p \leq v$ and $p<c \leq v$ then the seller threatens to invoke the defense but, since performance is actually efficient, parties renegotiate, the buyer ending up with payoff $\alpha \cdot(v-c)$. (2c) If $p \leq v$ and $v<c$ then the seller is excused from performing and non-performance is efficient. In this subcase, the buyer

itatively the same results could be established as in the case where the breach remedy is expectation damages. 
ends up with payoff zero. Integrating over $c$ leads to the same formula as in the previous case.

Notice,

$$
\lim _{s \uparrow s^{n}} \phi(v, s) \geq \lim _{s \downarrow s^{n}} \psi(v, s)
$$

and, hence, the buyer's payoff is continuous as a function of precautions except possibly at $s=s^{n}$ where it may jump downwards. Moreover, it is continuous as a function of the benefit $v$.

The following proposition can be established.

Proposition 6 (deterministic benefits)

(a) If $V\left(r^{*}\right) \leq p$ then the seller has efficient precaution incentives.

(b) If $p<V\left(r^{*}\right)$ then the seller has efficient (excessive, insufficient) precaution incentives if $s^{n}=s^{*}\left(s^{*}<s^{n}\right.$, or $s^{n}<s^{*}$, respectively) holds.

(c) If $s^{n} \leq s^{*}$ then the seller has efficient (excessive, insufficient) reliance incentives provided that $p=V\left(r^{*}\right)\left(V\left(r^{*}<p\right.\right.$, or $p<V\left(r^{*}\right)$, respectively).

Under deterministic benefits, qualitatively the same incentives emerge as under the interpretation of the defense based on inefficiency (see Proposition 3). In particular, if parties have specified price $p=V\left(r^{*}\right)$ for performance and if courts do impose a moderate precaution standard, $s^{n} \leq s^{*}$, then the legal regime generates efficient investment incentives for both parties. Since the proof of the above proposition parallels the one of Proposition 3, details are left to the reader.

In the case of uncertain benefits, the legal regime still generates efficient reliance incentives as the following proposition establishes but precaution incentives may be distorted.

\section{Proposition 7 (uncertain benefits)}

(a) If $s^{*}<s^{n}$ then the seller has excessive precaution incentives whereas, if $s^{n}=s^{*}$, he has weakly excessive precaution incentives.

(b) Suppose the buyer's cost function $H(r)$ and the cumulative distribution function $G(v, r)$ are both convex in reliances $r$. If the precaution standard is not excessive, more precisely if $s^{n} \leq s^{*}$ then there exists a unique price $p^{*}$ such that the buyer has efficient reliance incentives. If $p<p^{*}\left(p^{*}<p\right)$ then the buyer has insufficient (excessive) reliance incentives.

(c) If $s^{*}<s^{n}$ then the buyer has excessive reliance incentives. 
The proof proceeds along similar lines as the one of Proposition 4 and, for that reason, is omitted. I reproduce, however, the crucial partial derivatives:

$$
\begin{aligned}
& U_{s}\left(r^{*}, s\right) \\
= & \int_{p}^{M}\left(\beta \cdot F_{s}(p, s)+\alpha \cdot F_{s}(c, s)\right) \cdot(1-G(v, r)) \cdot d v- \\
& -\int_{0}^{p}\left(\beta \cdot F_{s}(p, s)+\alpha \cdot F_{s}(c, s)\right) \cdot G(v, r) \cdot d v
\end{aligned}
$$

and

$$
\Delta_{r}\left(r, s^{*}\right)=-\beta \cdot \int_{0}^{M}(F(v, s)-F(p, s)) \cdot G_{r}(v, r) \cdot d v
$$

It follows from the second equation that a unique price $p^{*}$ must exist such that $\Delta_{r}\left(r^{*}, s^{*}\right)=0$. This price generates efficient reliance incentives for the same reason as in Proposition 4. Yet the sign of $U_{s}\left(r^{*}, s^{*}\right)$ remains ambiguous. For that reason, excessive precaution incentives cannot be ruled out, not even if the precaution standard $s^{n}$ is defined at the efficient level $s^{*}$.

\section{Conclusion}

Breach remedies and performance excuses are default rules provided by contract law to fill gaps. Parties to a contract may have deliberately left such gaps in order to economize on transaction costs. Yet, rational parties will anticipate ex post effects from default rules when deciding on ex ante investments. Hence, default rules indirectly affect investment decisions such that alternative default rules may be compared on the basis of investment incentives which they generate.

In the present paper, incentives for precaution and reliance investments have been investigated which are generated by such default rules. By assumption, the parties have signed a simple fixed price contract in spite of the fact that costs of and benefits from performance are uncertain at the contracting stage. Nonetheless, by agreeing on the appropriate fixed price, efficient investment incentives for both parties are generated if the breach remedy of expectation damages is combined with an impracticability excuse based on the seller's non-profitability of performance. In contrast, the impracticability defense based on inefficiency of performance, let alone the one where the costs of performance are required to exceed the benefits by a larger margin has been shown to distort reliance incentives quite generally. 
In any case, the findings of the present paper support the view expressed by Posner (2008) that the case for strict liability for breach of contract is not particularly strong. Adding elements from a fault based negligence regime may well improve investment incentives which otherwise would remain distorted.

\section{References}

Ackermann, T. (2002), "Die Nacherfüllungspflicht des Stückverkäufers," Juristenzeitung $8,378-385$.

Cooter, R. (1985), "Unity in Tort, Contract, and Property: The Model of Precaution," California Law Review 73, 1 - 51.

Köndgen, J. (2008), "Die Entlastung des Schuldners wegen Unmöglichkeit der Leistung - Versuch einer Ehrenrettung des $\S 275$ Abs. 2 BGB", in: Eger, T. et al. (eds.): Internationalisierung des Rechts und seine ökonomische Analyse. Gabler: Wiesbaden.

Kornhauser, L.A. (1983), "Reliance, Reputation, and Breach of Contract", Journal of Law and Economics 26, 691 - 706.

Posner. R.A. and A.M. Rosenfield (1977), "Impossibility and Related Doctrines in Contract Law: An Economic Analysis", Journal of Legal Studies $6,83-118$.

Posner, E.A. (2008), "Fault in Contract Law," posted at the eScholarship Repository, University of California.

Rogerson, W.P. (1984), "Efficient reliance and damage measures for breach of contract," RAND Journal of Economics 15, 39 - 53 .

Schweizer, U. (2005), "Law and Economics of Obligations," International Review of Law and Economics 25, 209 - 228.

Shavell, S. (1980), "Damage measures for breach of contract", Bell Journal of Economics 11, $466-490$.

Sykes, A.O. (1990), "The Doctrine of Commercial Impracticability in a Second-Best World," Journal of Legal Studies 19, 43 - 94. 
Wagner, G. (1995), "In Defense of the Impossibility Defense", Loyola University of Chicago Law Journal 27, $55-95$. 